\title{
Added sugars and nutrient density in the diet of elderly Danish nursing home residents
}

\author{
Anne Marie Beck and Lars Ovesen \\ Danish Veterinary and Food Administration, Moerkhoej Bygade 19, DK-2860 Soeborg, Denmark.
}

Abstract

Background: Nursing home residents may be offered food and drinks with a high content of added sugars to increase their energy intake.

Objective: To analyse the influence of "empty calories" on the nutrient density, energy intake and body mass index of elderly Danish nursing home residents.

Design: The nutrient intake of 104 residents aged 83 (80-85) years was assessed using 4 day dietary records.

Results: Twenty-seven (26\%) residents had an intake of added sugars $<10 E \%, 41$ (39\%) between 10 and $20 E \%$, and $36(35 \%) \geq 20 E \%$. A significant decrease in nutrient density for dietary fibre, vitamins $\mathrm{A}, \mathrm{D}$, $\mathrm{E}$, thiamine, $\mathrm{B}_{6}$, folate and $\mathrm{B}_{12}$, and the minerals iron, zinc and iodine was observed as sugar concentration rose across the three groups. A negative relation was found between high levels of added sugars and intake of energy $(p<0.05)$.

Conclusions: A high intake of added sugars may adversely influence the intake of essential nutrients, and should be restricted in the diet of elderly nursing home residents, and be replaced by food and drinks with a high content of energy and micronutrients.

Keywords: Empty calories, energy intake, micronutrients.

Submitted: 18 February 2002; Revised: 3 April 2002; Accepted: 23 April 2002

\section{Introduction}

Studies among children have shown that many have a high intake of added sugars, and as the dietary content of added sugars rises, densities of several essential nutrients decline (1), and the body mass index (BMI) and frequency of obesity increase (2).

Elderly people residing in nursing homes comprise another group that may have a high intake of added sugars. Old people are potentially at risk of low micronutrient intakes and status because energy requirements decline with age, while most micronutrient requirements remain unchanged (3). Hence, dietary quality becomes more important at lower energy intake. In addition, many nursing home residents suffer from eating dependency, chewing and swallowing problems, and low body mass index (BMI) (4) and, hence, may be offered food and drinks with a high content of added sugars (and fat) to increase energy intake. The intake of desserts and cakes in general also seems to be higher than among free-living old people (5).
Many studies have found inadequate dietary intakes and low biochemical levels of macronutrients and micronutrients among nursing home residents (e.g. 5-9). Unfortunately, none of these studies provided information about the intake of added sugars.

The purpose of this study was to examine the influence of added sugars on the nutrient density, energy intake and BMI of elderly Danish nursing home residents.

\section{Method}

\section{Participants}

The participants were people aged $\geq 65$ years living in three nursing homes (NH1-NH3) in the Copenhagen area. The recruitment was performed by means of an enquiry to nursing homes that had previously shown an interest in nutrition. They all agreed to participate. Hence, a total of 105 nursing home residents could be invited to participate. The 
ethics committee of Copenhagen approved the study protocol and all participants or their relatives gave informed consent.

\section{Definitions}

The term "added sugars" refers to refined and industrially produced sugars (usually sucrose) used as ingredients in processed foods or added in the kitchen or at the table. Added sugars do not include naturally occurring monosaccharides and disaccharides in fruit, juices, vegetables and milk.

\section{Weight, height and body mass index}

All participants were weighed to the nearest $100 \mathrm{~g}$. Owing to mobility problems self-reported information about height was used. Seven of the nursing home residents had their height measured since they could not remember it. The height information was verified through medical case notes, nursing records, relatives and passports. BMI was calculated on the basis of the information about height and body weight.

\section{Energy and nutrient intake}

The participants had their energy intake assessed by means of a 4 days' estimated dietary record (either Wednesday to Saturday or Sunday to Wednesday) using household measures. Preprinted record sheets were used with information about the food served during the registration period and free space for extra foods. The participants and the health-care personnel received instructions from a registered dietician (AMB) in how to fill in the dietary record, with special focus on leftovers. The dietician was present, and supervised and aided the staff during the registration periods. Dietary records were inspected and ambiguous entries clarified (e.g. fat content in milk, use of butter on bread). Standardized household measures and average portions were used to assess food portion size if information was missing (10). The dietary record method has been used in several other published studies (e.g. 11-13). The energy intake was calculated using the computer program DANKOST 2000 (Danish Catering Centre), which is based on the Danish food composition tables and includes factors for cooking losses (14). In addition, the percentage of energy $(E \%)$ from added sugars was calculated. The micronutrients chosen for examination were those known to be associated with a diet of inadequate quality in relation to the intake of added sugars $(15,16)$.
Nutrient density was expressed as nutrients per MJ. The results were compared with the Nordic Nutrient Recommendations for planning of diets (NNR), i.e. the recommended nutrient values per $\mathrm{MJ}$ (\%NNR $\mathrm{MJ}^{-1}$ ) for $\geq 61$-year-old people (using the NNR for males 61-75 years) (3). Differences in nutrient density across three groups of added sugars ( $<10 E \%, 10-20 E \%$ and $\geq 20 E \%$ ) were examined.

\section{Estimated energy requirement}

The individual energy requirement was estimated using the Schoefield equations to calculate the basal metabolic rate (BMR) by means of information about age and body weight. The result was multiplied by the estimated physical activity level (PAL) (3). Distinction was made between participants who were bed-ridden $(\mathrm{PAL}=1.1)$, wheelchair-bound $\quad(\mathrm{PAL}=1.2)$, housebound $(\mathrm{PAL}=1.3)$ and able to move outdoors $(\mathrm{PAL}=$ 1.4) (3). Energy intake/BMR was compared with the cut-off limit of 1.1, below which it is unlikely that the energy intake represents either habitual intake or random low intake (17).

\section{Statistics}

The energy intake, nutrient density and BMI among residents with an intake of added sugars $<10 E \%$ and $\geq 20 E \%$ were compared using the Mann-Whitney test. The Kruskal-Wallis test was used to compare differences among all three groups ( $<10 E \%, 10-20 E \%$ and $\geq 20 E \%$.) Prevalences (\%) were compared by the $\chi^{2}$-test. Linear regression on log-transformed data was used to assess the relations between concentrations of added sugars, BMI and energy intake.

Microsoft Excel 2000 was used as statistical software. Two-sided $p$-values $<5 \%$ were considered significant. Data are presented as median $[95 \%$ confidence interval (CI)] or prevalence $(\%)$.

\section{Results}

One nursing home resident did not want to participate. Therefore, a total of 104 residents participated in the study. Their characteristics are presented in Table 1.

The level of added sugars was on average 16.9 (14.2-19.9) $E \%$ and the major sources were from table sugar added to coffee and fruit syrup drinks. Thirty-six (35\%) residents had an intake of added sugars $\geq 20 E \%, 41(39 \%)$ between 10 and $20 E \%$, and $27(26 \%)<10 E \%$. A comparison between the three groups with regard to energy intake, esti- 
Table I. Characteristics of participants in the three nursing homes (NHI-NH3)

\begin{tabular}{lcccc}
\hline Nursing home & $\mathrm{n}$ & $\begin{array}{c}\text { Males } \\
(\%)\end{array}$ & $\begin{array}{c}\mathrm{Age}^{\mathrm{a}} \\
(\text { years })\end{array}$ & BMI $^{\mathrm{a}}$ \\
\hline $\mathrm{NHI}$ & 22 & $6(27)$ & $84(82-85)$ & $21.6(19.4-25.6)$ \\
$\mathrm{NH} 2$ & 18 & $1(6)$ & $79(73-85)$ & $21.5(19.1-26.4)$ \\
$\mathrm{NH3}$ & 64 & $18(28)$ & $84(80-86)$ & $21.3(20.2-23.1)$ \\
Total & 104 & $25(24)$ & $83(80-85)$ & $21.3(19.9-23.6)$ \\
\hline
\end{tabular}

BMI: body mass index.

${ }^{a}$ Median (95\% confidence interval).

mated energy requirement, BMI and nutrient density (nutrient per $\mathrm{MJ}$ ) of selected micronutrients is presented in Table 2. There was no difference in the three groups with regard to BMI, energy intake or the prevalence of underweight $(\mathrm{BMI}<20)$. A significant decrease in nutrient density for dietary fibre, vitamins $\mathrm{A}, \mathrm{D}, \mathrm{E}$, thiamine, $\mathrm{B}_{6}$, folate and $\mathrm{B}_{12}$, and the minerals iron, zinc and iodine was observed as sugar concentration rose across the three groups. In general, residents with an intake of added sugars $<10 E \%$ had higher nutrient density than those with an intake $\geq 20 E \%$. A total of seven $(7 \%)$ of the residents had an energy intake below $1.1 \times \mathrm{BMR}$, and in all groups the intake of the majority of the nutrients was below the recommendations for planning of diets.

The results of the linear regression analysis of the relations between concentration of added sugars, BMI and energy intake are presented in Table 3. Energy intake increased with an increase in BMI. In contrast, energy intake decreased slightly with an increased energy percentage from added sugars.

\section{Discussion}

This study found a high prevalence (74\%) of nursing home residents with an intake of added sugars above the recommended level $(10 E \%)$ (3). A significant decrease in nutrient density for dietary fibre, vitamins $A, D, E$, thiamine, $B_{6}$, folate and $B_{12}$, and the minerals iron, zinc and iodine was observed as sugar concentration rose across the three groups of

Table 2. Comparison of energy intake, body mass index (BMI) and density of some important nutrients between residents with an intake of added sugars < I0E\%, $10-20 \mathrm{E} \%$ and $\geq 20 \mathrm{E} \%$

\begin{tabular}{|c|c|c|c|c|c|c|}
\hline & \multirow{2}{*}{$<\mathrm{IOE} \%$ sugar } & \multirow[t]{2}{*}{$10-20 \mathrm{E} \%$ sugar } & \multirow{2}{*}{$\geq 20 \mathrm{E} \%$ sugar } & \multicolumn{3}{|c|}{$<\mathrm{IOE} \%$ vs $\geq 20 \mathrm{E} \%$} \\
\hline & & & & $\mathrm{KW}$ p-value ${ }^{\mathrm{a}}$ & MW p-value ${ }^{b}$ & $N^{c}$ \\
\hline n (\%) & $27(26)$ & 4I (39) & $36(35)$ & - & - & \\
\hline BMI & $22.7(19.8-25.5)$ & $21.6(20.2-26.1)$ & $20.4(18.2-23.6)$ & ns & ns & \\
\hline $\mathrm{BMI}<20(\%)$ & $8(30)$ & $13(32)$ & $16(45)$ & - & $n s^{d}$ & \\
\hline Energy intake ( $M J$ day $\left.^{-1}\right)$ & $7.3(6.5-8.0)$ & $7.7(6.9-8.4)$ & $6.6(5.6-7.9)$ & ns & ns & \\
\hline BMR & $5.2(4.9-5.8)$ & $4.9(4.7-5.4)$ & $4.7(4.5-5.0)$ & $<0.05$ & $<0.05$ & \\
\hline PAL & $1.3(1.2-1.4)$ & $1.3(1.2-1.4)$ & $1.2(1.15-1.3)$ & ns & ns & \\
\hline Energy intake $<\mathrm{I} . \mathrm{I} \times \mathrm{BMR}(\%)$ & I (4) & 0 & $6(17)$ & - & - & \\
\hline Added sugars (E\%) & $4.7(3.0-7.3)$ & $16.5(14.8-17.2)$ & $23.4(21.9-25.8)$ & $<0.001$ & $<0.001$ & \\
\hline Fibres $\left(g \mathrm{MJ}{ }^{-1}\right)$ & $2.2(1.9-2.5)$ & $1.7(1.6-1.8)$ & $1.5(1.3-1.6)$ & $<0.001$ & $<0.001$ & 3.0 \\
\hline Vitamin A (RE $\left.\mathrm{MJ}^{-1}\right)$ & $143(127-155)$ & $140(115-155)$ & $104(81-123)$ & $<0.001$ & $<0.001$ & 130 \\
\hline Vitamin $D\left(\mu g \mathrm{MJ}^{-1}\right)$ & $0.33(0.30-0.39)$ & $0.32(0.30-0.36)$ & $0.26(0.20-0.30)$ & $<0.001$ & $<0.001$ & $0.70^{\mathrm{e}}$ \\
\hline Vitamin $E\left(\alpha-T^{-1} \mathrm{MJ}^{-1}\right)$ & $0.61(0.55-0.69)$ & $0.56(0.53-0.63)$ & $0.49(0.44-0.55)$ & $<0.001$ & $<0.001$ & 1.50 \\
\hline Thiamine $\left(\mathrm{mg} M \mathrm{JJ}^{-1}\right)$ & $0.11(0.10-0.11)$ & $0.10(0.09-0.11)$ & $0.09(0.08-0.10)$ & $<0.01$ & $<0.01$ & 0.17 \\
\hline Riboflavin (mg MJ-1) & $0.21(0.18-0.26)$ & $0.20(0.18-0.23)$ & $0.19(0.16-0.22)$ & ns & ns & 0.20 \\
\hline Vitamin $B_{6}\left(m g \mathrm{MJ}^{-1}\right)$ & $0.14(0.12-0.16)$ & $0.13(0.11-0.14)$ & $0.11(0.10-0.12)$ & $<0.001$ & $<0.001$ & 0.20 \\
\hline Folate $\left(\mu \mathrm{g} \mathrm{MJ}{ }^{-1}\right)$ & $27(25-31)$ & $27(24-28)$ & $23(2 \mid-25)$ & $<0.001$ & $<0.001$ & 43 \\
\hline Vitamin $B_{12}\left(\mu \mathrm{g} \mathrm{MJ}^{-1}\right)$ & $0.63(0.55-0.74)$ & $0.58(0.49-0.64)$ & $0.47(0.40-0.52)$ & $<0.001$ & $<0.001$ & 0.29 \\
\hline Vitamin $C\left(m g \mathrm{MJ}^{-1}\right)$ & $6.8(5.5-9.5)$ & $7.2(6.0-8.8)$ & $5.9(5.3-6.7)$ & ns & ns & 8.6 \\
\hline Calcium (mg $\mathrm{MJ}^{-1}$ ) & $148(113-181)$ & $139(125-152)$ & $127(106-163)$ & ns & ns & 115 \\
\hline Iron (mg MJ-1) & $1.04(0.96-1.16)$ & $0.91(0.85-0.98)$ & $0.85(0.76-0.92)$ & $<0.001$ & $<0.001$ & 1.40 \\
\hline Zinc (mg $\mathrm{MJ}^{-1}$ ) & $1.27(1.19-1.45)$ & $1.12(1.05-1.17)$ & $0.99(0.96-1.04)$ & $<0.001$ & $<0.001$ & 1.30 \\
\hline lodine $\left(\mu g \mathrm{MJ}^{-1}\right)$ & $13.3(9.2-16.8)$ & $9.3(8.5-10.7)$ & $9.5(8.7-10.8)$ & $<0.05$ & $<0.01$ & 27.0 \\
\hline
\end{tabular}

BMR: basal metabolic rate; PAL: physical activity level.

Data are $\mathrm{n}(\%)$ or median (95\% confidence interval).

${ }^{a}$ Kruskal-Wallis; ${ }^{b}$ Mann-Whitney; ${ }^{c}$ ND: nutrient density calculated for $\geq 61$-year-old people (see Method section); ${ }^{d} \chi^{2}$-test; ${ }^{e}$ calculation based on a recommendation of $5 \mu \mathrm{g}$ day $^{-1}$. 
Table 3. Relations between concentration of added sugars, body mass index (BMI) and energy intake assessed by means of linear regression on log-transformed data

\begin{tabular}{lll}
\hline & $\beta$ & $P$ \\
\hline BMI vs energy intake & 0.55 & 0.001 \\
E\% added sugars vs BMI & -0.04 & 0.21 \\
E\% added sugars vs energy intake & -0.11 & 0.024 \\
\hline
\end{tabular}

added sugars $(<10 E \%, 10-20 E \%$ and $\geq 20 E \%)$ (Table 2). A negative relation was found between levels of added sugars in the diet and intake of energy (Table 3).

No other studies have examined the intake of added sugars among nursing home residents. However, the present findings are in contrast to studies among free-living old people, which found an intake of added sugars around $10 E \%(16,18,19)$. One explanation for this discrepancy could be that these studies used different dietary record methods $(18,19)$ and different definitions of the term "added sugars" (16). Another could be the high prevalence of nutritional risk factors known to exist among nursing home residents, e.g. poor oral health, dysphagia and eating dependency $(4,20)$, all of which could lead to a decreased intake of energy and of "healthy" foods (fruits, vegetables, meat, etc.) with a high content of micronutrients. A third explanation could be the pervasive problem of underreporting of food intake, which is known to occur with dietary surveys. This, among other things, may resolve the disagreement about whether a direct link exists between a high intake of added sugars and increased rates of obesity among adults $(15,16)$. The significant relation $(p=$ 0.001 ) between energy intake and BMI (Table 3) and the low percentage of participants with energy intake $<1.1 \times$ BMR (Table 2) do not support underreporting in this study.

A minimum of 4 days of dietary recording is required to rank energy and sugar intake with acceptable precision (21). A much longer registration period is needed to assess individual intakes of the majority of micronutrients, because of the skewed distribution of these nutrients in the diet (3, 21). One reason for choosing a registration period of 4 days was that a longer period was believed to be too demanding for the participants. Another reason was that old people in general have a more stable food pattern (smaller day-to-day variation) than younger adults (22). This was also the case in the present study, where the within-subject coeffi- cient of variation was $13.4 \%$ and the between-subject coefficient of variation was $15.4 \%$ (calculations not shown).

In all groups the intake of the majority of nutrients per MJ was below the recommended level for planning of diets (Table 2). This is in accordance with the findings in other studies (5-9) and is often related to an intake of energy below the recommended level $(5,7)$.

In this study seven (7\%) of the residents had an energy intake below $1.1 \times$ BMR and $37(36 \%)$ had a BMI $<20$. A rise in content of added sugars apparently had a negative impact on both energy intake and nutrient densities (Tables 2, 3).

In conclusion, a high intake of added sugars may adversely influence the nutritional quality of the diet and the intake of essential nutrients. Foods rich in added sugars and "empty calories" should be restricted in the diet of elderly nursing home residents, and be replaced by food and drinks with a high content of energy and micronutrients.

\section{References}

1. Lyhne N, Ovesen L: Added sugars and nutrient density in the diet of Danish children. Scand J Nutr 1999;43:47.

2. Ludwig DS, Peterson KE, Gortmaker SL: Relation between consumption of sugar-sweetened drinks and childhood obesity: a prospective observational analysis. Lancet 2001;357:505-8.

3. Sandström B, Aro A, Becker W, Lyhne N, Pedersen JI, Thórsdóttir I: Nordic Nutrient Recommendations 1996. Copenhagen: Nordic Council of Ministers, 1996: 28. (In Swedish.)

4. Morley JE, Silver AJ: Nutritional issues in nursing home care. Ann Intern Med 1995;123:850-9.

5. Löwik MRH, Schneijder P, Hulshof KFAM, Sleutel L, van Houten P: Institutionalised elderly women have lower food intake than do those living more independently (Dutch Nutrition Surveillance System). J Am Coll Nutr 1992;11:432-40.

6. Sahyoun NR, Otradovec CL, Hartz SC, Jacob RA, Peters H, Russel RM, McGandy RB: Dietary intakes and biochemical indicators of nutritional status in an elderly, institutionalised population. Am J Clin Nutr 1988;47:524-33.

7. Wielen RPJ van der, Wild GM de, Groot LCPGM de, Hoefnagels WHL, van Staveren WA: Dietary intakes of energy and water-soluble vitamins in different categories of aging. J Gerontol 1996;51A:B100-7.

8. Rudman D, Abbasi AA, Isaacson K, Karpiuk E: Observations on the nutrient intakes of eating-dependent nursing home residents. Underutilisation of micronutrient supplements. J Am Coll Nutr 1995;14:604-13.

9. Johnson RM, Smiciklas-Wright H, Soucy IM, Rizzo JA: Nutrient intake of nursing-home residents receiving 
pureed foods or a regular diet. J Am Geriatr Soc 1995;43:344-8.

10. Andersen LT, Jensen H, Haraldsdóttir J. Typical weights of foods. Scand J Nutr 40(Suppl 32): S129-52.

11. Beck AM, Ovesen L: Body mass index, weight loss and energy intake of old Danish nursing home residents and home-care clients. Scand J Caring Sci 2002;16:86-90.

12. Beck AM, Ovesen L: Modification of the nutrition questionnaire for elderly to increase its ability to detect elderly people with inadequate intake of energy, calcium, vitamin $\mathrm{C}$ and vitamin D. Eur J Clin Nutr 1999;53:560-9.

13. Beck AM, Ovesen L, Schroll M: Validation of the Resident Assessment Instrument triggers in the detection of undernutrition. Age Ageing 2001;30:161-5.

14. Saxholt E: Food composition tables. 4th edn. National Food Agency, 1996. (In Danish.)

15. Johnson RK, Fray C: Choose beverages and foods to moderate your intake of sugars: the 2000 Dietary Guidelines for Americans - what's all the fuss about? J Nutr 2001;131:S2766-71.

16. Gibson S: Dietary sugars and micronutrient dilution in normal adults aged 65 years and over. Publ Health Nutr 2001;4:1235-44.

17. Black AE, Coward WA, Cole TJ, Prentice AM: Human energy expenditure in affluent societies: an analysis of 547 doubly labelled water measurements. Eur J Clin Nutr 1996;50:72-92.
18. Andersen NL, Fagt S, Groth MV, Hartkopp HB, Moller A, Ovesen L: Dietary habits in Denmark. Main results. Publication no. 235. National Food Agency, 1996. (In Danish with English summary.)

19. Alstad T, Österberg T, Rothenberg E, Steen B, Birkhed D: Intake of monosaccharides, sucrose and fibre in the elderly - a cross-sectional and longitudinal study. Scand J Nutr 1999;43:147-52.

20. Vellas B, Guigoz Y, Garry PJ, Nourhashemi F, Bennahaum D, Lauque S, Albarede J-L: The Mini Nutritional Assessment (MNA) and its use in grading the nutritional state of elderly patients. Nutrition 1999;15:11622.

21. Nelson M, Black AE, Morris JA, Cole TJ: Between and within-subject variation in nutrient intake from infancy to old age: estimating the number of days required to rank dietary intakes with desired precision. Am J Clin Nutr 1989;50:155-67.

22. Nes M, Staveren WA van, Zajkás G, Inelmen EM, Moreiras-Varelaa O: Validity of the dietary history method in elderly subjects. Eur J Clin Nutr 1991; 45(Suppl 3): 97-104.

Anne Marie Beck

Danish Veterinary and Food Administration, Moerkhoej Bygade 19, DK-2860 Soeborg, Denmark. Tel: + 45339565 I0; Fax: + 45339566 96; E-mail: be@fdir.dk 